\section{Esophagobronchial fistula following injection sclerotherapy for esophageal varices}

We report on two cases of esophagobronchial fistulae, which developed following endoscopic variceal injection sclerotherapy (EVIS) for bleeding esophageal varices due to schistosomal periportal fibrosis (SPPF). Both patients underwent successful surgical repair and had an uneventful outcome.

The first patient was a 22-year-old male who presented with cough following oral fluid intake for the past 2 years. The condition developed after three sessions of EVIS. Barium swallow ( $\bullet$ Fig. 1 ) and upper gastrointestinal endoscopy confirmed a fistula opening in the middle esophagus and communicating with the branches of the right lower bronchus. The patient underwent a right thoracotomy, and the fistula track was divided and repaired.

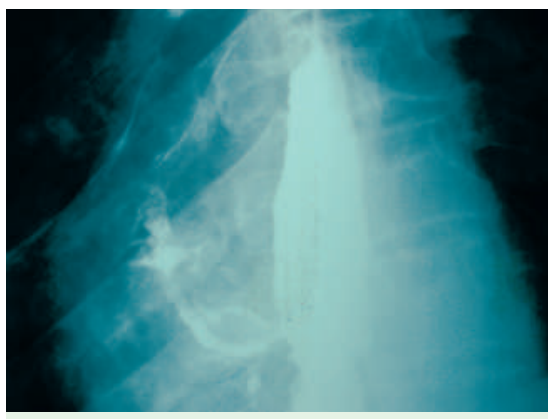

Fig. 1 Case 1: barium swallow showing the esophagobronchial fistula track.

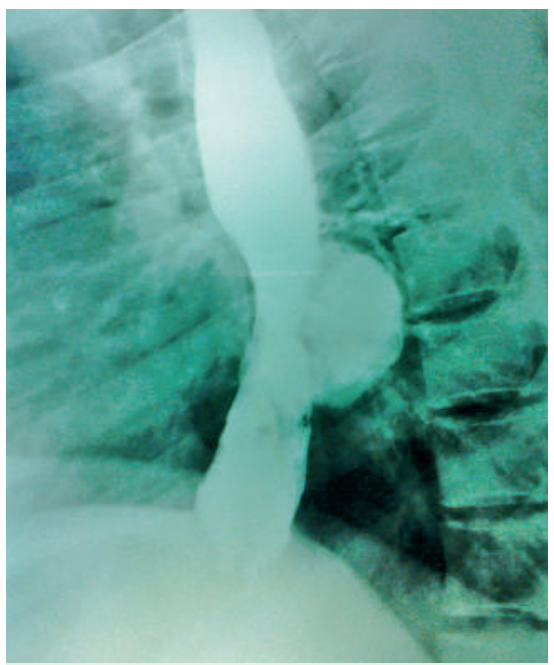

Fig. 2 Case 2: barium swallow showing the esophagobronchial fistula track.
The second patient was a 32-year-old female who presented with recurrent attacks of cough following fluid intake. The condition developed after seven sessions of EIVS for SPPF 4 years previously. Barium swallow ( $\bullet$ Fig. 2 ) and upper gastrointestinal endoscopy ( $\bullet$ Fig. 3) showed a fistula track between the lower esophagus and lower lobe bronchus. Through a right thoracotomy the tract was identified, divided, and repaired ( $\bullet$ Fig. 4).

EVIS and rubber band ligation are the two main standard procedures for control of variceal bleeding due to portal hypertension [1] but they are sometimes associated with complications [2], which can be serious, such as bleeding, pleural effusion, pericardial effusion with cardiac tamponade and esophageal perforation [3]. The reported incidence of esophageal stricture following EVIS in Sudan was 3\%, and there were two cases $(0.2 \%)$ of fatal

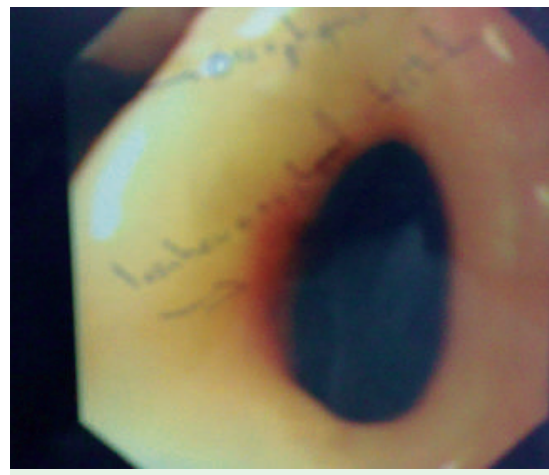

Fig. 3 Endoscopic view of the fistula orifice in Case 2.

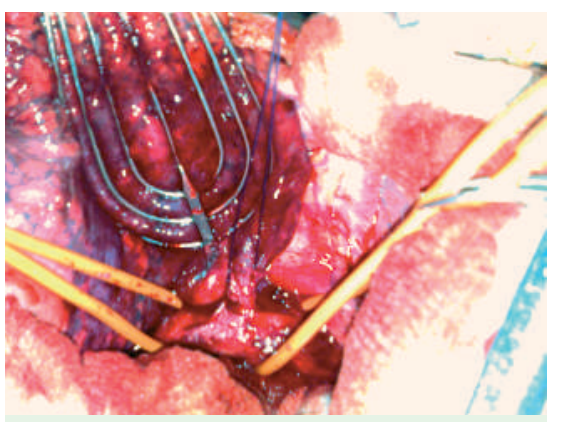

Fig. 4 Right thoracotomy view: the fistula track is held with a blue thread and the esophagus is held with two yellow tapes above and below the track. perforation [4]. Surgical treatment is preferable. Endoscopic obliteration of both the bronchial and esophageal ends of a congenital bronchoesophageal fistula with local application of sodium hydroxide and acetic acid has been recommended for patients who are unfit for thoracotomy [5].

To our knowledge, these are the first reported cases of successful repair of esophagobronchial fistulae following EVIS for esophageal varices due to schistosomal periportal fibrosis.

\section{Endoscopy_UCTN_Code_CPL_1AH_2AC}

\section{S. I. Mahadi, A. M. A. Derweesh, M. E. Ahmed}

Department of Surgery, Faculty of Medicine, University of Khartoum, Sudan

\section{References}

1 Westaby D, MacDougall BR, Williams R. Improved survival following injection sclerotherapy for oesophageal varices: final analysis of a controlled trial. Hepatology 1985; 5: $827-830$

2 Sivak MV. Oesophageal varices. In: Sivak MV (ed). Gastrointest Endosc 1987: 363 - 368

3 Carr-Locke DL, Sidky K. Broncho-esophageal fistula: a late complication of endoscopic variceal sclerotherapy. Gut 1982; 23: 1005-1007

4 Fedail SS. Esophageal varices in Sudan. Gastrointest Endosc 2002; 56: 781 - 782

5 Weissberg D, Kaufman M. Bronchoesophageal fistula in adults: congenital or acquired. J Thorac Cardiovasc Surg 1990; 99: $756-757$

\section{Bibliography}

DOI $10.1055 / s-2007-995378$

Endoscopy 2008; 40: E59

(c) Georg Thieme Verlag KG Stuttgart · New York . ISSN 0013-726X

\section{Corresponding author}

\section{E. Ahmed, MD}

Department of Surgery

Khartoum University Medical School

PO Box 102

Khartoum 102

Sudan

Fax: +249-18-3782663

rasheid@usa.net 